\title{
Power Loss and Operating Temperature of Tires
}

\author{
R. D. Stiehler, M. N. Steel, G. G. Richey, J. Mandel, and R. H. Hobbs
}

(June 19, 1959)

\begin{abstract}
The power loss of pneumatic tires was measured under steady-state conditions by means of two dynamometers, one of which measured the total power input and the other power output. A steel wheel was used to measure the power loss in the equipment and in windage. The power required to flex the tire (input power minus output power minus equipment and windage losses), was not affected by the tractive effort (output power). The coefficient of rolling resistance, a dimensionless quantity, was calculated by means of the equation: $R=(P / S L)$, where $P$ is power loss of tire, $S$ is speed, and $L$ is load. This coefficient increased at an increasing rate with the slip angle (angle between plane of tire and direction of travel) and was approximately doubled at an angle of 2 degrees.

The change in $R$ with speed varied and appeared to depend on construction of the tire. Both nylon and steel wire truck tires exhibited a decrease in $R$ with speed, rayon truck tires showed either no change or a linear increase in $R$ with speed, and for passenver car tires $R$ increased at an increasing rate with speed, particularly for a rayon tire. $R$ increased with load for all but the steel wire tire. The change in $R$ with inflation pressure was studied only for rayon truck tires. $R$ increased linearly with the reciprocal of the pressure but the rate was dependent on the speed and load conditions.

The type of rubber had a pronounced effect on $R$ and combinations of natural and styrenebutadiene rubber caused $R$ to be larger than expected from the values of $R$ for tires made from a single rubber. Varying the type of carbon black in the treads of truck tires had no effect on $R$, but SAF black in passenger car tires caused $R$ to be larger than that when HAF black was used. Because of constructional differences, no conclusions on effect of cord could be drawn. However, $R$ for a steel wire truck tire was the lowest observed, and the values for rayon tires were lower than those for nylon tires except at high speeds.

The temperature rise of the air in the inner tube was found to be related to the power loss by the relation: $\Delta T / P=G+H /(S L)^{0.8}$ where $G$ and $H$ are parameters dependent on the thermal resistance of the rubber compounds and of the interface between tire and air or roadway, respectively. The ratio $\Delta T / P$ remained essentially unchanged by changes in inflation pressure and did not appear to be affected by the type of cord.
\end{abstract}

\section{Introduction}

Work is required to flex a tire as it rotates. This work is converted into heat which increases the temperature until the rate of heat dissipation equals the rate of heat generation or power loss in a tire. In large tire sizes, the resulting high operating temperature is a serious problem. It shortens the life of a tire and is the principal deficiency of synthetic rubber for use in these tires. Even natural rubber is far from an ideal rubber in this respect.

The importance of power loss and its effect on operating temperature has long been realized. However, a survey of the rubber literature reveals few systematic studies published on this subject since the early work of Holt and Wormeley [1] ${ }^{2}$ in 1922 and 1923. The paper by Billingsley et al. [2] in 1942 and that by Evans [3] in 1948 are perhaps the most comprehensive of those published in the last 20 years. The importance of this problem in the Government Synthetic Rubber Program led to a resumption of work on power loss of tires at the National Bureau of Standards in 1948 after a lapse

1 This paper was presented at the International Rubber Conference, Washington, D.C., Nov. 8 through $13,1959$.

2 Figures in brackets indicate the literature references at the end of this paper. of over 20 years. This paper summarizes the work of the past 10 years on the measurement of power loss and the resultant operating temperature in pneumatic tires.

\section{Equipment}

The basic method of Holt and Wormeley [1] was used in these studies. Since the equipment used by them was no longer available, new equipment was constructed which differed in some respects from that used in the early work.

The arrangement of the equipment is shown schematically in figure 1. Dynamometer A having a capacity of $60 \mathrm{hp}$ at $250 \mathrm{rpm}$ is connected to a standard smooth-face steel drum (D), 1/300 mile in circumference and $14 \mathrm{in}$. in width. This dynamometer is operated as a generator and provides the desired tractive effort.

Dynamometer B has a capacity of $40 \mathrm{hp}$ at 250 rpm and is operated as a motor in measuring the power loss of truck and bus tires. It is connected through universal joints to one axle of a truck rear wheel assembly on which the tire ( $\mathrm{T}$ ) is mounted. The rear axle housing is suspended from the ceiling by means of two rods approximately 20 - $\mathrm{ft}$ long; the tire and wheel assembly are supported like a ballistic 


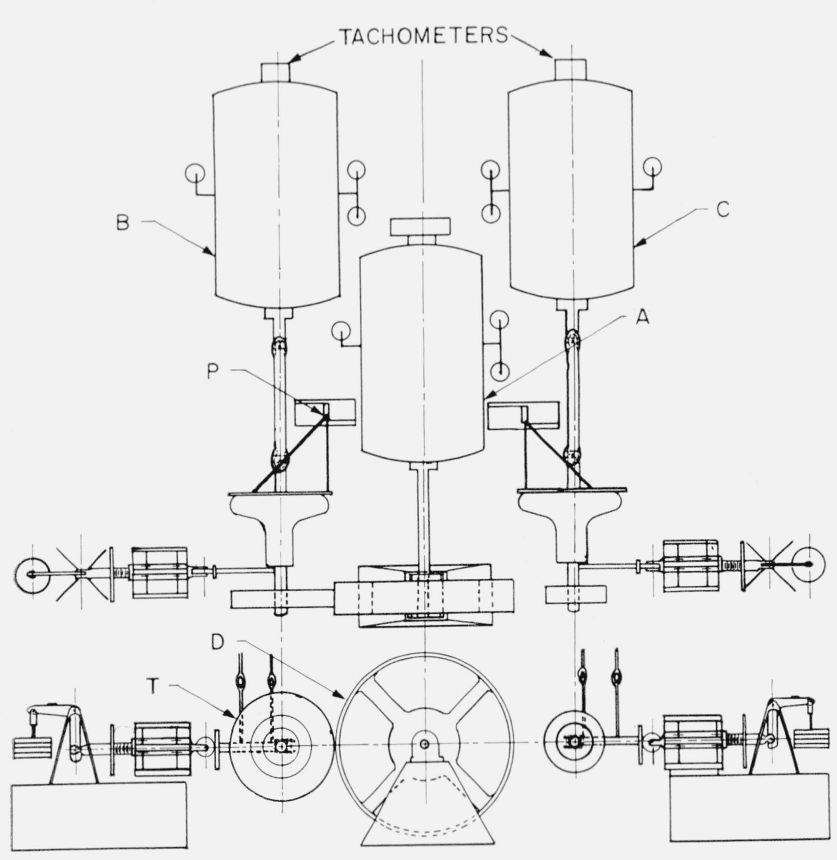

Figure 1. Schematic arrangement of equipment for measuring power loss of tires.

(A) Absorption dynamometer connected to steel drum, D; (B) Dynamometer used for driving truck tire, T; (C) Dynamometer used for driving passenger car tire; (P) Ball and socket pivot used for alining the plane of tire with the plane of the drum.

pendulum. The assembly is pivoted in a ball and socket joint located in the vertical plane tangent to the steel drum (point $\mathrm{P}$ in fig. 1). The pivot point can be adjusted vertically which rotates the plane of the tire and permits its alinement with the plane of the steel drum. The pivot also prevents axial motion of the tire. Adjustments are provided for keeping the axes of rotation for tire and steel drum parallel during test under any load. Radial motion in the horizontal plane is restrained by the load applied to the tire. The load is applied by means of weights acting through a lever arm so that the load on the tire is approximately four times the applied load. This loading system is almost free of friction, being under $10 \mathrm{lb}$ or less than 1 percent of the applied load. (Note: Initially the load was applied to the axle housing through a conventional leaf spring. The friction and power loss in the spring made it necessary to revert to an unsprung load.)

Dynamometer $\mathrm{C}$ has a capacity of $20 \mathrm{hp}$ at 700 rpm and is operated as a motor in measuring the power loss of passenger car tires. The arrangement is the same as that described for truck tires. Either dynamometer $\mathrm{B}$ or $\mathrm{C}$, but not both, is used in conjunction with dynamometer $\mathrm{A}$ in any one test. Each dynamometer is instrumented to permit measurement of speed within $0.1 \mathrm{rpm}$ or 0.2 percent at the slowest speed and of torque on the armature shaft within $0.1 \mathrm{lb}-\mathrm{ft}$ or 1 percent of the difference between input and output torques.

The tire and steel drum are enclosed in a housing. The temperature of the air within the housing is controlled at $100^{\circ} \pm 5^{\circ} \mathrm{F}$. The temperature of the air contained within the tire is measured by means of a copper-constantan thermocouple which extends beyond the valve stem into the tire approximately 0.7 the distance between the rim and crown of the tire. The thermocouple is connected to a recorder through a compensating circuit and copper slip-rings as described by Richey, Hobbs, and Stiehler [4]. The valve stem is connected through a rotating joint to a precision pressure gage for measuring the inflation pressure.

\section{Calibration of Equipment}

A calibrated pressure gage accurate to within 0.1 $\mathrm{lb} / \mathrm{in}^{2}$ was used to measure the pressure within the tire. The copper-constantan thermocouples were calibrated using a benzoic acid cell [5] and found to be within $1^{\circ} \mathrm{F}$ of the correct temperature. The power loss in the bearings, in windage, and in other parts of the equipment was determined by means of a steel tire assembly constructed in the following manner:

An annular steel ring about 40 in. in outside diameter and 1 in. in thickness was mounted on a 20-in. tire rim. Wood blocks were fastened to the sides of the steel ring. A 9.00-20 tire was split and fastened to the rim and wood blocks so that the completed assembly appeared like a tire mounted on a rim with a center steel rib extending about $1 / 8$ in. above the tire. This assembly was mounted in place of the truck tire and the circumference of the steel ring was machined true. A similar assembly was constructed for determining power loss in the equipment when testing passenger car tires.

The power loss of each system was measured with these steel tires at a combination of speeds and loads ranging from 10 to $60 \mathrm{mph}$ and 600 to $5,000 \mathrm{lb}$. It was found that the equipment power loss could be expressed as a polynominal function of speed and load in accordance with the following equation, where $P$ represents power loss, $S$ speed, and $L$ load:

$$
P=a S+b S^{2}+c S^{3}+d L S
$$

Using dynamometers A and B, the best values for the parameters $a, b, c$, and $d$, derived by the method of least squares from a total of 40 measurements, are as follows:

$$
\begin{aligned}
& a=96.4 \\
& b=4.26 \\
& c=0.0644 \\
& d=.0288
\end{aligned}
$$

when power loss is expressed in feet-pounds per minute, speed in miles per hour, and load in! pounds.

\section{Procedure}

Since the power loss of a new tire decreases rapidly during the first few hours of running and then changes 
at a much slower rate, the tires were preconditioned by running them for at least $16 \mathrm{hr}$ at $45 \mathrm{mph}$ under 80 to 100 percent of maximum rated load.

After preconditioning, the load, speed, and inflation pressure were adjusted to the desired values for test; the axle of the rotating tire was made parallel to the axle of the steel drum; and the tire was run until the temperature of the contained air remained constant within $1^{\circ} \mathrm{F}$ for at least $10 \mathrm{~min}$. Readings were then taken of the torque on the dynamometers, their speed, and the inflation pressure. The readings were repeated about $5 \mathrm{~min}$ later. The temperature of the ambient air and of the contained air were recorded. This procedure was repeated for the next combination of load, speed, and inflation conditions.

The sequence of measuring the various combinations of load, speed, and inflation was varied in accordance with a statistical design in order to eliminate systematic bias.

The measured values of power loss were corrected for power loss in the equipment and windage as determined from eq (1). For convenience in comparing tires, the dimensionless quantity-hereinafter called coefficient of rolling resistance or $R$-was derived from the corrected power loss by the following equation:

$$
R=\frac{P}{88 S L}
$$

where $P$ is power loss in feet-pounds per minute, $S$ is speed in miles per hour, and $L$ is load in pounds.

\section{Tractive Effort}

A few measurements were made on the effect of tractive effort on power loss. The results for a tire made from natural rubber (NR) and one made from styrene-butadiene rubber (SBR) are given in table 1 . Over the range of tractive effort studied, there is no evidence of any change in power loss. Measurements on tires used in the treadwear study by Mandel, Steel, and Stiehler [6] also indicate no change in power loss with tractive effort. These results are not in accord with those of Billingslev et al. [2] and Holt and Wormeley [1]. No explanation for the difference in results is apparent.

The creep was determined in these experiments by means of the equation

$$
C=(l-2 \pi r) / l,
$$

where $l$ is the distance the tire travels in one revolution and $r$ is the measured rolling radius. The creep remained constant with increasing tractive effort. It was positive and amounted to about 2 percent, being slightly greater at $50 \mathrm{mph}$ than at $20 \mathrm{mph}$.

Since it was easier to adjust the speed with some tractive effort on the tire, all subsequent measurements were made with a constant tractive torque of $52.5 \mathrm{lb}-\mathrm{ft}$ (630 lb-in.), corresponding to 0.5 and 2.5 hp at speeds of 10 and $50 \mathrm{mph}$, respectively.

\section{Slip Angle}

The power loss of the tires in table 1 was also measured at several angles, ranging from $0^{\circ}$ to $2^{\circ}$ between the plane of the tire and the plane of the steel drum. The coefficients of rolling resistance measured at each condition of test are given in table 2. Since the values for the two speeds are practically identical, their averages are plotted in figure 2 as a function of the slip angle. The results in table 2 and figure 2 show that the increase in rolling resistance is not dependent on the speed and is practically the same for the two types of rubber.

TABLE 1. Effect of tractive effort on power loss 9.00-20, 10 ply tires; load 4,000 lb; inflation pressure $90 \mathrm{lbs} / \mathrm{in}^{2} .^{2}$ gage; ambient

\begin{tabular}{|c|c|c|c|c|}
\hline \multirow{2}{*}{ Tractive torque ${ }^{\mathrm{a}}$} & \multicolumn{4}{|c|}{ Power loss in horsepower } \\
\hline & NR & & SB1 & tire \\
\hline $\begin{array}{r}\quad l b-i n \\
315 \\
630 \\
945 \\
1,260 \\
1,575 \\
1,890 \\
2,205\end{array}$ & $\begin{aligned} 20 \mathrm{mph} \\
1.33 \\
1.34 \\
1.32 \\
1.32 \\
1.33\end{aligned}$ & $\begin{aligned} 50 \mathrm{mph} \\
3.29 \\
3.29 \\
3.28 \\
3.23 \\
3.26 \\
3.24 \\
3.28\end{aligned}$ & $\begin{array}{rr}20 \mathrm{mph} \\
2.08 \\
2.07 \\
2.10 \\
2.07 \\
2.08\end{array}$ & $\begin{array}{r}50 m p h \\
5.08 \\
5.13 \\
5.11 \\
5.09 \\
5.13 \\
5.15 \\
5.17\end{array}$ \\
\hline
\end{tabular}
temperature $100^{\circ} \mathrm{F}$

a On output dynamometer.

TABLE 2. Effect of slip angle on rolling resistance 9.00-20, 10 ply tires; load 4,000 lb; inflation pressure $90 \mathrm{lbs} / \mathrm{in}^{2}$ gage; ambient temperature $100^{\circ} \mathrm{F}$

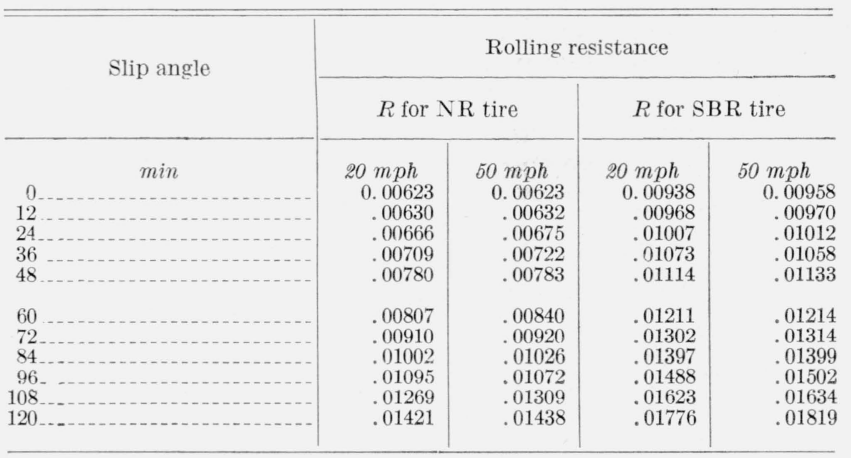

As the slip angle increases from $0^{\circ}$ to $2^{\circ}$, the rolling resistance and power loss approximately doubles. At the same time, there is only a slight increase in the temperature of the air contained within the inner tube. These results lead to the conclusion that the increase in power loss with slip angle is dissipated at the interface between tire tread and steel drum. There is a large increase in temperature at the interface as manifested by the amount of liquified rubber appearing on the drum. The heat generated at the interface is dissipated mainly through the drum so that the temperature of the air within the tire is only slightly affected. Since the increase in rolling resistance is practically the same for the two types of tires, their coefficients of friction against steel must be alike or nearly so. 


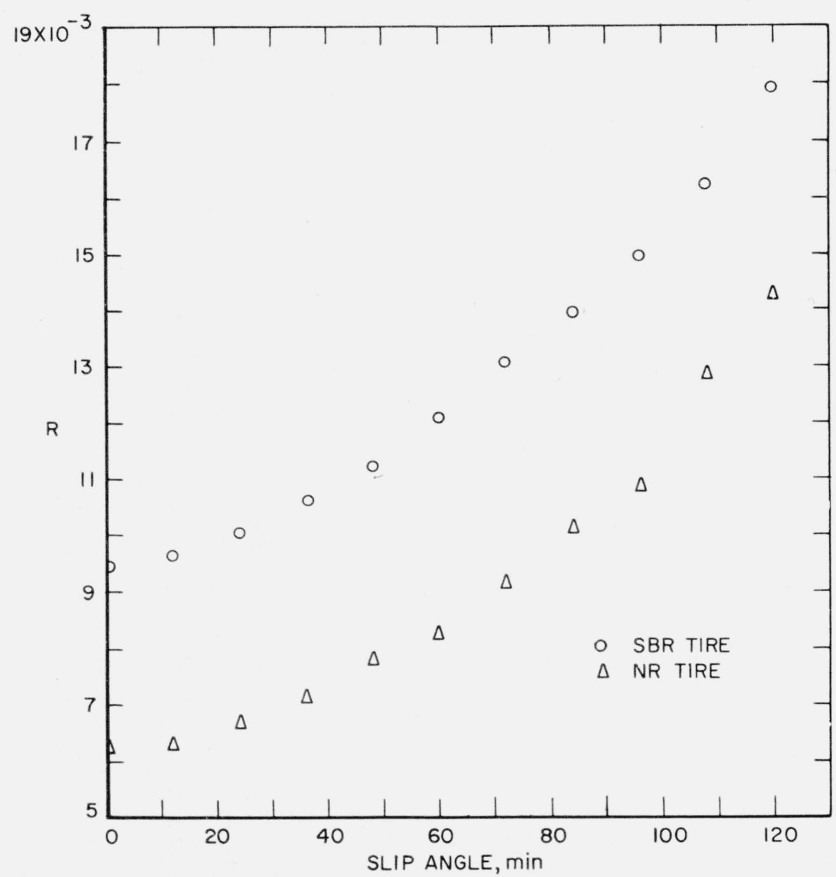

Figure 2. Effect of slip angle on coefficient of rolling resistance, $R$, for 9.00-20, 10-ply truck tire.

\section{Speed and Load}

Information on the effect of speed and load was obtained from two comprehensive experiments, denoted in the following discussion as experiments $\mathrm{A}$ and $B$. Experiment A employed 9.00-20, 10-ply tires and experiment B employed 10.00-20, 12-ply tires.

\section{Experiment $A$}

(9.00-20, 10-Ply Tires)

This study was made on the following four experimental tires involving different combinations of two types of rubber in the tread and in the carcass.

\begin{tabular}{c|c|c}
\hline \hline Tire construction & Tread & Carcass \\
& & \\
& NR & NR \\
NR & SBR \\
& SBR & NR \\
& SBR & SBR \\
\hline
\end{tabular}

Two tires of each construction were tested. In each run the inflation pressure of the tire was set initially at 90 psi at a temperature of $100^{\circ} \mathrm{F}$. No further pressure adjustment was made during the run. The experiment was carried out in two parts. First each tire was run at speeds of $5,10,20,30,40$, and $50 \mathrm{mph}$ under constant loads of 1,000 and 4,000 lb. Then, the speed was held constant at each of two levels, 10 and $50 \mathrm{mph}$, while the tire was run under loads of 500,1,000,2,000, 3,000, 4,000, and 5,000 lb.

The mean values of the coefficients of rolling resistance are listed in table 3 for duplicate tires of each construction. The standard deviation for experimental error, determined from the differences between the results obtained on duplicate tires tested under the same conditions, is 0.00038 for these data. Thus, the uncertainty in the values given in table 3 is in the second significant figure. However, for purposes of statistical analysis three significant figures are retained.

Using this estimate as a standard of reference, several mathematical formulas were tried to express the coefficient of rolling resistance as a function of speed and load. It was found that the following relation fitted the data within experimental error:

$$
R=R_{0}+B(S)+C(L)+D(S L) .
$$

TABLE 3. Experiment A: Coefficients of rclling resistance for experimental tires

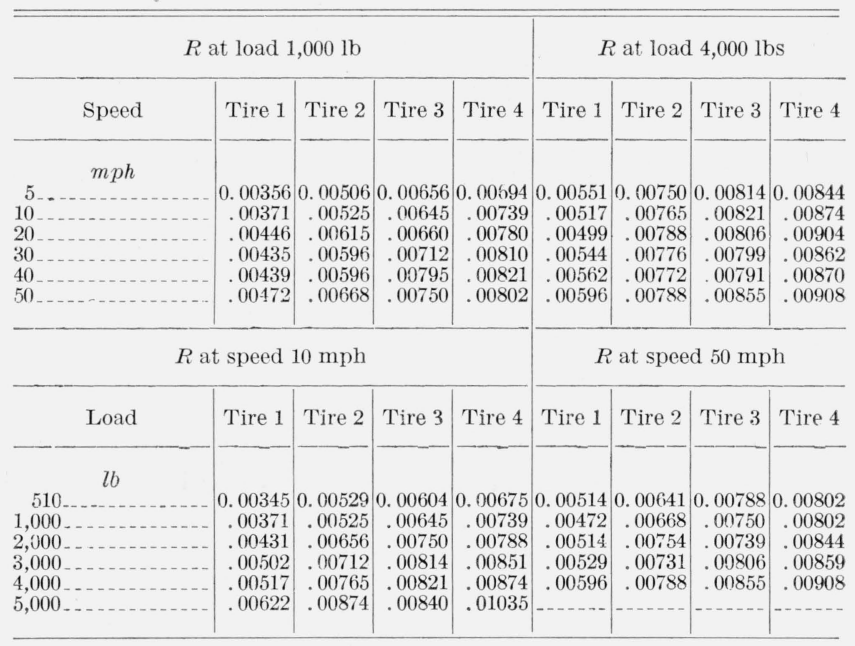

In this equation, $S$ represents speed in miles per hour, and $L$, load in pounds. The constants $R_{0}, B$, $C$, and $D$ were derived from the data by the method of least squares. Values for $B, C$, and $D$, given in table 4, are nearly alike for the four tire constructions.

A statistical analysis shows that the differences are not significant on the basis of the evidence provided by the experiment. Of course, more comprehensive data might reveal significant differences for these parameters, but it is unlikely that the differences would be of practical importance. For these reasons, it is assumed that the value of each coefficient in eq (3) has the same value for each construction. The best statistical estimates of $B$, $C$, and $D$ based on this assumption are listed in the last line of table 4. As expected, the parameter $R_{0}$ varies with the construction. This parameter is discussed in section 10 .

It may be inferred from eq (3), and from the constancy of $B, C$, and $D$ for all four constructions that the quantity $R-R_{0}$ depends only on speed and load. Consequently, when $R-R_{0}$ is plotted against either speed or load, the points should follow the same curve for all four constructions. Figures 3 and 4 are plots of the average of $R-R_{0}$ versus speed and load, respectively. The straight lines represent 
Table 4. Experiment A: Parameters in eq 3

\begin{tabular}{|c|c|c|c|}
\hline Tire construction & $\mathrm{B}$ & $\mathrm{C}$ & $\mathrm{D}$ \\
\hline $\begin{array}{l}1 \\
2 \\
3 \\
4\end{array}$ & $\begin{array}{l}30.8 \times 10^{-6} \\
38.4 \\
32.0 \\
26.4\end{array}$ & $\begin{array}{l}0.559 \times 10^{-6} \\
.835 \\
.579 \\
.607\end{array}$ & $\begin{array}{l}-0.00421 \times 10^{-6} \\
-.00878 \\
-.00570 \\
-.00613\end{array}$ \\
\hline Alla $\ldots$. & 33.8 & 0.642 & 0.00708 \\
\hline
\end{tabular}

a Best statistical estimate on assumption of single values for B, C, and D.

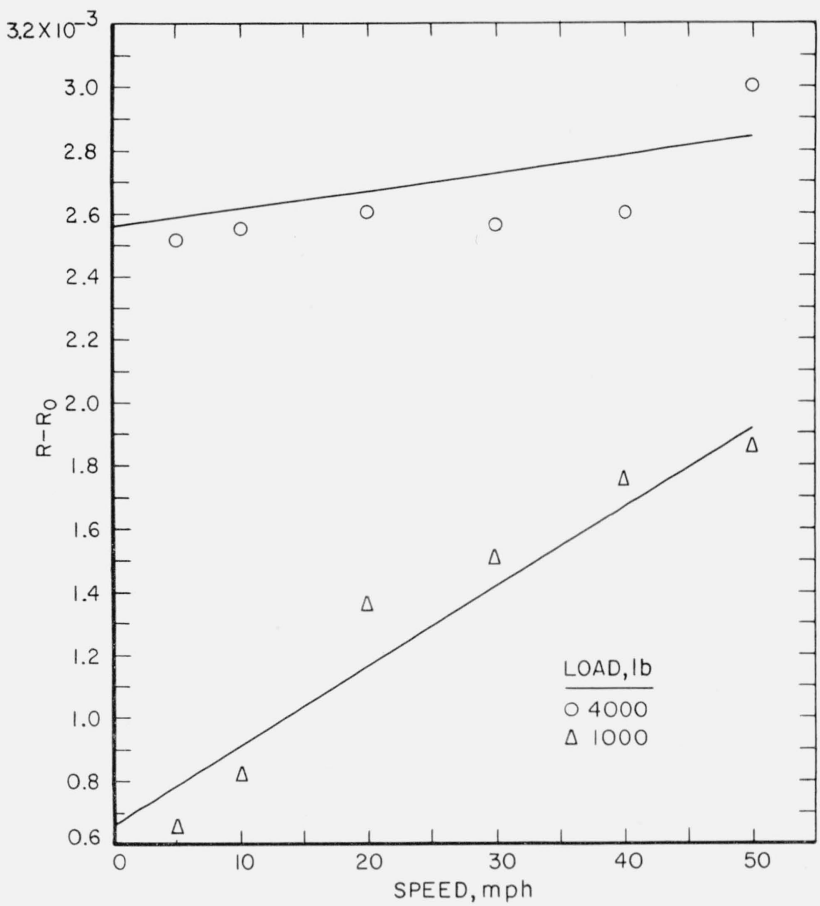

Figure 3. Increase in coefficient of rolling resistance, $R-R_{0}$, with speed for 9.00-20, 10-ply truck tire (experiment $A$ ).

eq (3), using the values for all constructions in table 4. In general, the effects of speed and load given by eq (3) are in satisfactory agreement with the experimental results. The difference in the slopes of the two lines in each graph is related to the last term in eq (3), containing the product of speed and load, with a negative coefficient.

\section{Experiment B}

(10.00-20, 12-ply tires)

In this experiment, one tire from each of five commercial brands was run at five different speeds and five different loads. The pressure was held constant at 105 psi at running temperature. The speeds were $10,20,30,40$, and $50 \mathrm{mph}$; the loads were 1,000 , $2,000,3,000,4,000$, and 5,000 lb. Thus, 25 speedload combinations were run on each of 5 tires. In order to eliminate possible biases due to time and order of running, a graeco-latin square design was used with respect to the factors tire, speed, load, and order.

To test the adequacy of eq (3) for the representa-

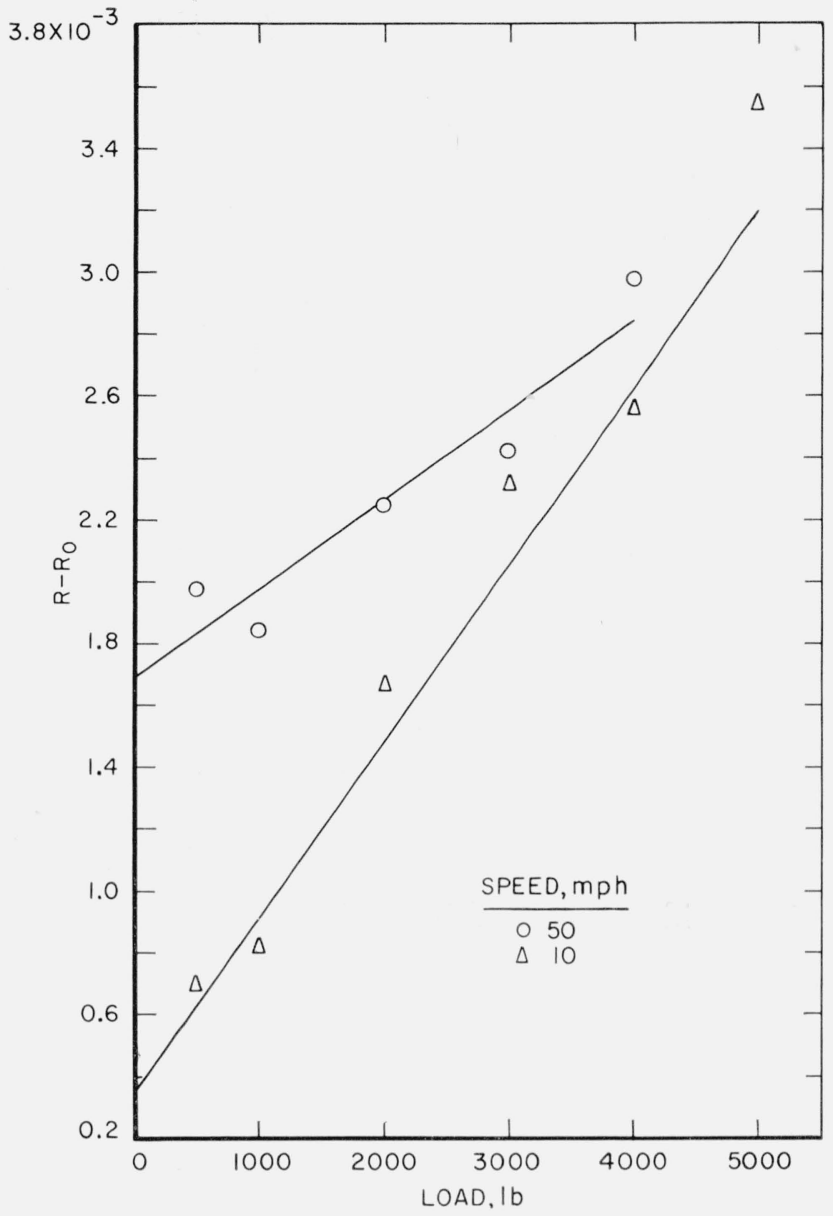

FIgURE 4. Increase in coefficient of rolling resistance, $R-R_{0}$, with load for 9.00-20, 10-ply truck tires (experiment $A$ ).

tion of the data yielded by experiment $\mathrm{B}$, an analysis of variance was made for the data corresponding to each tire. The results are summarized in table 5 . The "linear" part of the speed mean square corresponds to the term $B(S)$ in eq (3); the "linear" part of the load mean square corresponds to the term $C(L)$; and the "linear $\times$ linear" part of the speed $X$ load interaction corresponds to the $D(S L)$ term.

In table 5, practically all nonlinear terms are of the order of magnitude of experimental error, the variance of which is $7.0 \times 10^{-8}$. This value corresponds to a standard deviation of the coefficient of rolling resistance of 0.00026 . This value is smaller than the one in experiment $A$. The difference may be due to the fact that the standard deviation in experiment A includes the variability between duplicate tires, whereas this estimate reflects only experimental error.

It can be inferred from table 5 that the data of experiment B are adequately represented by the following equation:

$$
R=R_{\mathrm{O}}+B(S)+C(L) .
$$


TABLE 5. Experiment B: Analysis of variance of speed and load effects on coefficient of rolling resistance

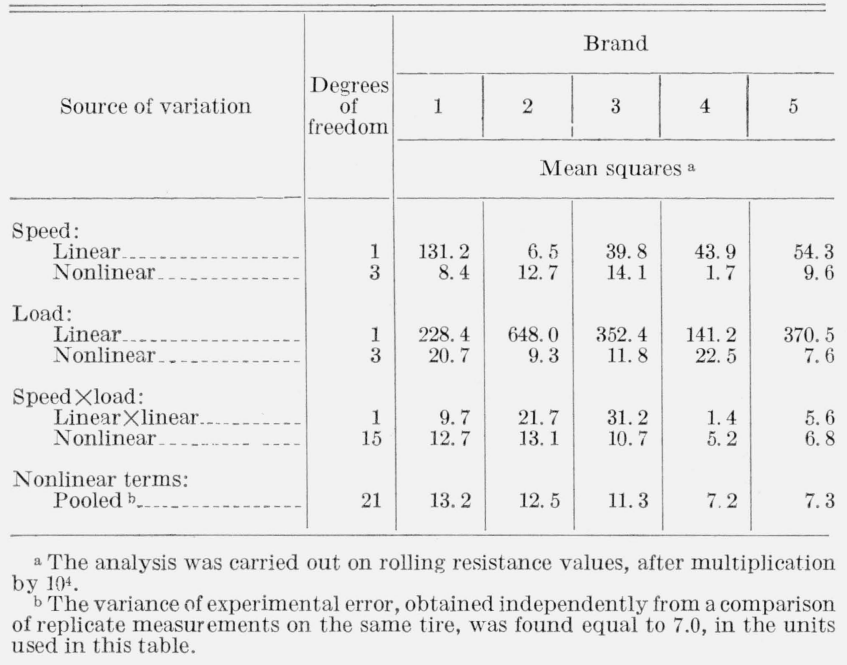

A term in $S L$ is unnecessary, since the mean square for the linear portion of the interaction of speed and load is of the order of experimental error for all tires. Moreover, in the case of brand 2, there is no evidence that variation in speed has any effect on rolling resistance. Table 6 gives the least squares estimates for the parameters $R_{0}, B$, and $C$ for the five brands; the value $B$ being made equal to zero in the case of brand 2 .

It may be concluded from the data in experiment A that the parameters $B, C$, and $D$ in eq (3) are, at most, only slightly affected by changes in the rubber compounds in the tire, but the data in experiment $\mathrm{B}$ show that the parameters $B$ and $C$ in eq (4) are appreciably influenced by other changes in construction.

Table 6. Experiment B: Parameters in equation (4) for five brands of tires

\begin{tabular}{|c|c|c|c|}
\hline Brand of tire & $B$ & $C$ & $R_{0}$ \\
\hline $\begin{array}{l}1 \\
2 \\
3 \\
4 \\
5\end{array}$ & $\begin{array}{l}\text { 16. } 2 \times 10^{-6} \\
0 \\
8.9 \\
9.4 \\
10.4\end{array}$ & $\begin{array}{l}0.214 \times 10^{-6} \\
.360 \\
.266 \\
.168 \\
.272\end{array}$ & $\begin{array}{l}\text { 3. } 824 \times 10^{-3} \\
\text { 3. } 315 \\
4.655 \\
4.127 \\
4.008\end{array}$ \\
\hline
\end{tabular}

\section{Inflation Pressure}

Measurements of power loss were made at several inflation pressures using tires 1 and 4 of experiment $A$ and brands 1, 2, 3, and 4 of experiment B. Five combinations of speed and load were used in the study with tires 1 and 4 . The rolling resistances given in table 7 were obtained. An analysis indicated that for each speed-load condition $R$ is essentially linearly related to the reciprocal of the pressure. The intercepts and slopes given in table 7 for each speed-load condition were calculated by the method of least squares. The agreement of these parameters with the data was good, as can be seen in figure 5. However, they indicated a large
TABLE 7. Effect of inflation pressure on rolling resistance 9.00-20, 10-ply tires; ambient temperature $100^{\circ} \mathrm{F}$

\begin{tabular}{|c|c|c|c|c|c|c|}
\hline \multirow{2}{*}{\multicolumn{2}{|c|}{$\begin{array}{l}\text { Speed } \\
\text { Load } \\
\text { Pressure (p) } 1,000 / \mathrm{p}\end{array}$}} & $\begin{array}{r}20 \\
1,000\end{array}$ & $\begin{array}{r}50 \\
1,000\end{array}$ & $\begin{array}{r}35 \\
2,500\end{array}$ & $\begin{array}{r}20 \\
4,000\end{array}$ & $\begin{array}{r}50 \\
4,000\end{array}$ \\
\hline & & \multicolumn{5}{|c|}{$R$ for NR Tire } \\
\hline $\begin{array}{r}7 b^{\prime} \text { in } \\
120 \\
105 \\
90 \\
75 \\
60\end{array}$ & $\begin{array}{r}8.3 \\
9.5 \\
11.1 \\
13.3 \\
16.7\end{array}$ & $\begin{array}{l}\text { 5. } 72 \\
5.81 \\
6.00 \\
6.00 \\
6.19\end{array}$ & $\begin{array}{l}\text { 5. } 14 \\
\text { 5. } 40 \\
5.59 \\
5.96 \\
6.49\end{array}$ & $\begin{array}{l}4.84 \\
4.89 \\
5.53 \\
5.98 \\
6.62\end{array}$ & $\begin{array}{l}5.34 \\
5.58 \\
6.09 \\
6.91 \\
7.90\end{array}$ & $\begin{array}{l}\text { 5. } 40 \\
\text { 5. } 58 \\
6.15 \\
6.91 \\
7.88\end{array}$ \\
\hline \multicolumn{2}{|c|}{$\begin{array}{l}\text { Intercept }(\mathrm{A})^{\mathrm{a}} \\
\text { Slope }(\mathrm{B})^{\mathrm{a}}\end{array}$} & 53 & $159^{3.84}$ & 225 & ${ }_{316}^{2 .} 64$ & $308^{2.75}$ \\
\hline & & \multicolumn{5}{|c|}{$R$ for $\mathrm{SBR}$ Tire } \\
\hline $\begin{array}{r}120 \\
105 \\
90 \\
75 \\
60\end{array}$ & $\begin{array}{r}8.3 \\
9.5 \\
11.1 \\
13.3 \\
16.7\end{array}$ & $\begin{array}{r}9.28 \\
9.34 \\
9.86 \\
\text { 10. } 35 \\
10.63\end{array}$ & $\begin{array}{r}7.87 \\
8.01 \\
8.62 \\
10.05 \\
9.81\end{array}$ & $\begin{array}{r}7.47 \\
7.87 \\
8.50 \\
9.30 \\
10.64\end{array}$ & $\begin{array}{r}7.90 \\
8.70 \\
9.42 \\
10.23 \\
11.71\end{array}$ & $\begin{array}{r}9.66 \\
10.05 \\
10.69 \\
11.97 \\
13.40\end{array}$ \\
\hline \multicolumn{2}{|c|}{$\begin{array}{l}\text { Intercept }(A)^{a} \\
\text { Slope }(B)^{a}\end{array}$} & $176^{7.82}$ & $27{ }^{5.64}$ & $\begin{array}{l}4.28 \\
380\end{array}$ & $\begin{aligned} 4.39 \\
441\end{aligned}$ & ${ }_{461}^{5.72}$ \\
\hline
\end{tabular}

Nоте: All values are rolling resistance multiplied by 1,000.

a Calculated by least squares to fit linear regression: $R=A+B / p$.

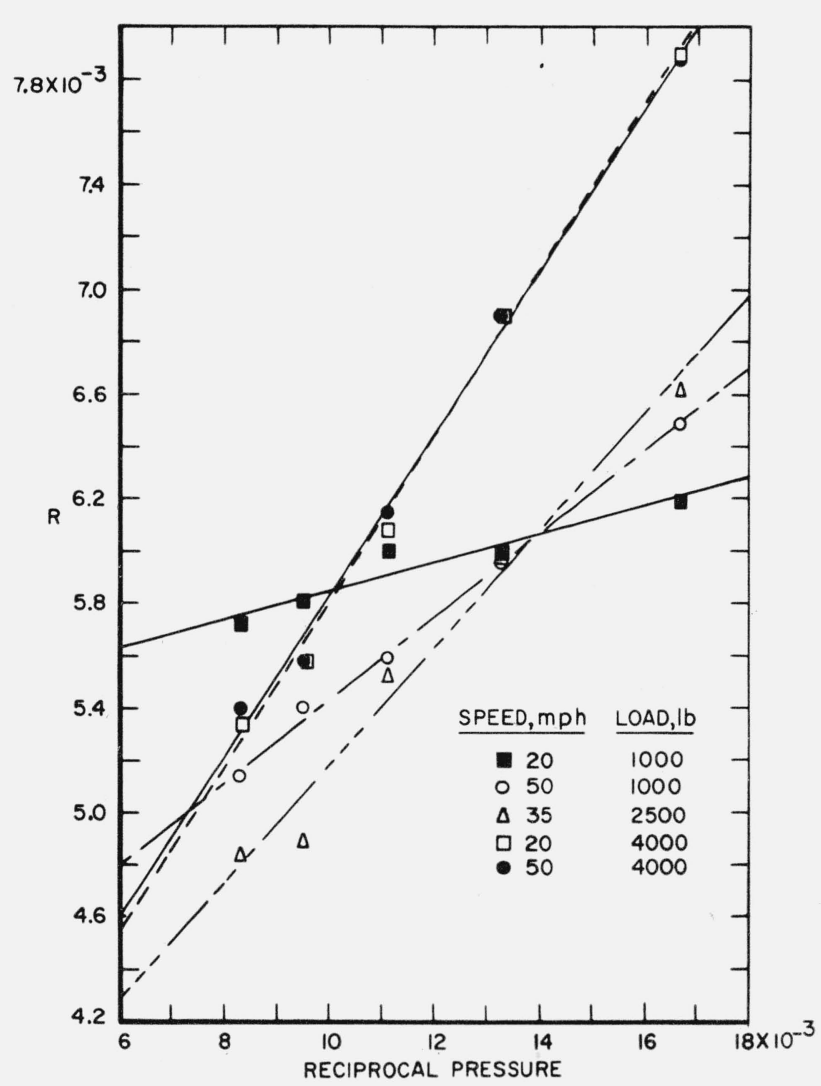

Figure 5. Effect of inflation pressure on coefficient of rolling resistance, $R$, for NR 9.00-20, 10-ply truck tire.

The reciprocal of the gage pressure in $\mathrm{lb} / \mathrm{in} .^{2}$ is used for the abscissa. 
interaction with speed and load which could not be resolved with the limited data available.

The results obtained with brands $1,2,3$, and 4 of experiment B confirmed the linear relationship between $R$ and the reciprocal of the inflation pressure. However, the large interaction with speed and load complicated the analysis of the data obtained with a $4 \times 4 \times 4$ graeco-latin square design.

Nevertheless, it appears that the effect of pressure on $R$ is practically independent of the speed at normal rated loads but markedly dependent on speed at low loads. On the other hand, the effect of pressure on $R$ increases with the load at all speeds, the rate of increase being more pronounced at low speeds.

\section{Variation Among Brands}

The variation among brands was determined from experiment B and two other experiments conducted at a speed of $45 \mathrm{mph}$. In one of these experiments, 6 brands of 9.00-20,10-ply tires were studied and in the other, 5 brands of 11.00-20, 12-ply tires.

Figure 6 represents eq (4) for the five brands included in experiment B at a fixed load of $5,000 \mathrm{lb}$, and figure 7 represents the same equation at a fixed speed of $50 \mathrm{mph}$. It is seen that distinct differences exist between some of the brands. The effect of speed on rolling resistance is far smaller than the effect of load. In view of the linearity of eq (4), the slopes of the lines drawn in figure 6 are independent of load. Thus, if a load other than 5,000 lb were selected, the straight line corresponding to each brand in figure 6 would be shifted parallel to itself, but the amount of the shift would vary from brand to brand. A similar conclusion holds for figure 7 . It is apparent from these two figures

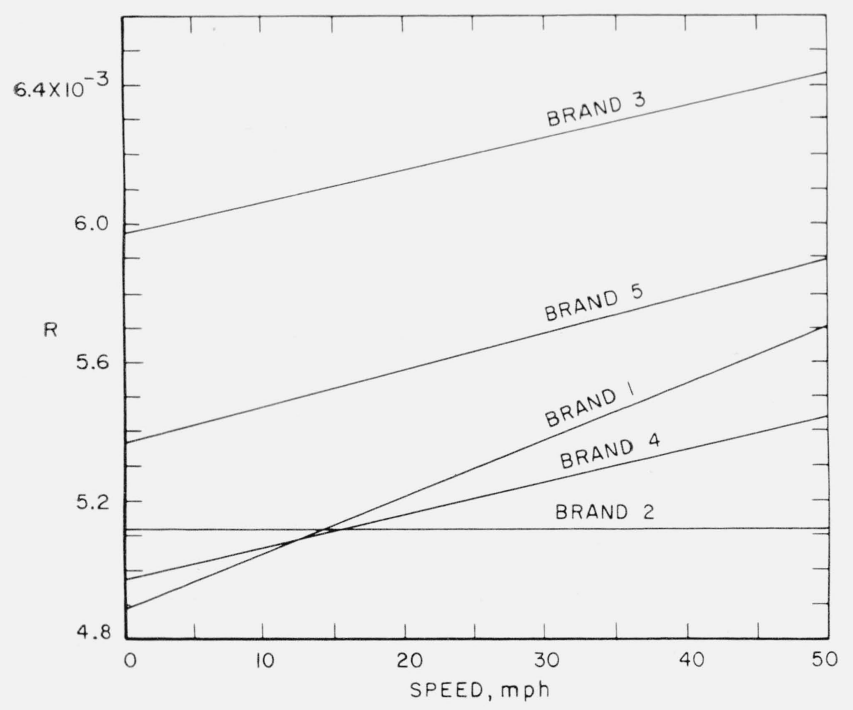

FIGURE 6. Effect of speed on coefficient of rolling resistance, $R$, for five different commercial brands of 10.00-20, 12-ply truck tires (experiment $B$ ).

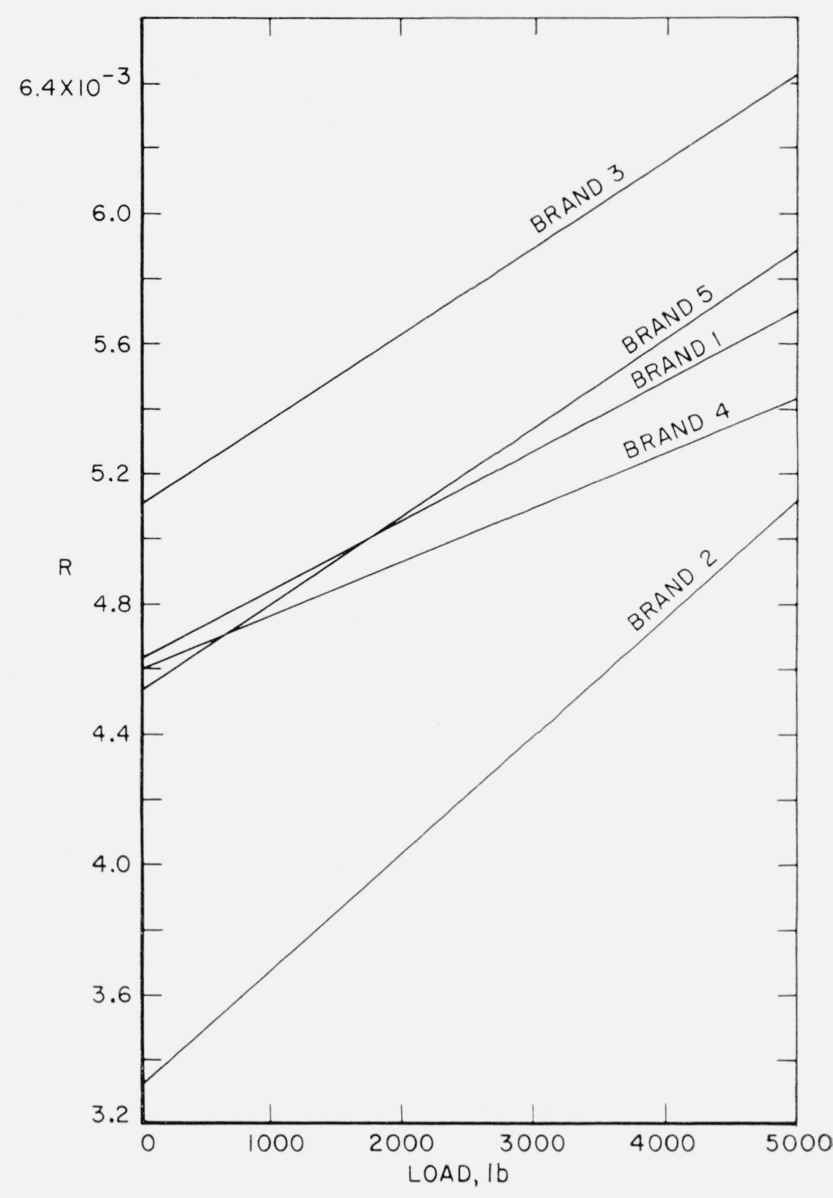

FiguRE \%. Effect of load on coefficient of rolling resistance, $R$, for five different commercial brands of 10.00-20, 12-ply truck tires (Experiment B).

that the relative coefficients of rolling resistance or power losses for various brands of tires are dependent on the speed and load at which the comparison is made.

A comparison of the results obtained in experiment $B$ with those obtained in the experiments at $45 \mathrm{mph}$ is given in table 8 . The values for experiment $\mathrm{B}$ are interpolated from eq (4) at a speed of $45 \mathrm{mph}$ and a load of 4,000 $\mathrm{lb}$. All values in the table were corrected for power loss in equipment and windage. It is seen that the three sets, representing three different sizes, show considerable consistency in the ranking of the brands with respect to power loss. The consistency is remarkable since the various sizes were produced at different times over a period of several years. Since the tires were not produced concurrently, definite conclusions cannot be drawn about the effect of size of the tire on power loss. However, it appears that the coefficients of rolling resistance should be approximately the same for different sizes at the same speed and under loads appropriate for the tire size. 
TABLE 8. Coefficients of rolling resistance for several brands and sizes

\begin{tabular}{|c|c|c|c|}
\hline \multirow{2}{*}{ Brand } & \multicolumn{3}{|c|}{ Size of tire } \\
\hline & $9.00-20,10$ ply & $10.00-20,12$ ply a & $11.00-20,12$ ply \\
\hline $\begin{array}{l}1 \\
2 \\
3 \\
4 \\
5\end{array}$ & $\begin{array}{l}6.03 \times 10^{-3} \\
5.54 \\
6.99 \\
5.54 \\
6.51 \\
6.51\end{array}$ & $\begin{array}{l}5.41 \times 10^{-3} \\
4.76 \\
6.12 \\
5.22 \\
5.56\end{array}$ & $\begin{array}{l}5.88 \times 10^{-3} \\
9.26 \\
6.18 \\
6.80 \\
9.36\end{array}$ \\
\hline $\begin{array}{l}\text { Speed } \\
\text { Load } \\
\text { Inflation }\end{array}$ & $\begin{array}{l}45 \mathrm{mph} \\
3,450 \mathrm{lb} \\
65 \mathrm{psig} \text { at } \\
100^{\circ} \mathrm{F}\end{array}$ & $\begin{array}{l}45 \mathrm{mph} \\
4,000 \mathrm{lb} \\
105 \mathrm{psig} \text { at } \\
\text { running } \\
\text { tempera- } \\
\text { ture }\end{array}$ & $\begin{array}{l}45 \mathrm{mph} \\
4,500 \mathrm{lb} \\
70 \mathrm{psig} \text { at } \\
100^{\circ} \mathrm{F}\end{array}$ \\
\hline
\end{tabular}

a Values calculated from eq (4).

\section{Type of Rubber}

Information on the influence of type of rubber on rolling resistance was provided by experiment $\mathrm{A}$ and by power loss measurements on the tires whose treadwear characteristics were reported by Mandel, Steel, and Stiehler [6]. Experiment A described in section 7 was primarily designed to determine the influence of the type of rubber and the relative contribution of carcass and tread to power loss. It was mentioned in that section that the parameter $R_{0}$ in eq (3) was the only one that varied significantly for the four constructions.

Table 9 lists the values of $R_{0}$ for the tires in experiment $A$. The standard error of these values is $0.13 \times 10^{-3}$. Accordingly, the differences in $R_{0}$ have only a small uncertainty due to error of measurement.

The difference in $R_{0}$ values for tires 1 and 3 is $2.7 \times 10^{-3}$ and that for tires 2 and 4 is $1.38 \times 10^{-3}$. Similarly, the difference for tires 1 and 2 is $2.04 \times 10^{-3}$ and that for tires 3 and 4 is only $0.72 \times 10^{-3}$. Thus, it is apparent that the contributions of the rubber in tread and carcass to power loss are not additive. Instead, there is a pronounced interaction between tread and carcass which causes the power loss to be greater than anticipated when SBR is present in either. Although quantitative conclusions concerning the relative contribution of tread and carcass are not possible, the data indicate that the greater power loss is in the tread. Considering only power loss, it appears advantageous to make 100 percent natural and synthetic rubber tires from the available rubber rather than to use one rubber in the carcass and the other in the tread.

Results of the tire constructions whose treadwear characteristics were reported by Mandel, Steel, and Stiehler [6] are given in table 10. These tires had natural rubber carcasses and differed only in the composition of the tread. In view of the interaction between tread and carcass, comparisons of these tires are only qualitative indices of the effect of rubber on power loss. Recognizing this limitation, the results show the pronounced increase in power loss when synthetic rubber is present.
TABLE 9. Effect of rubber in carcass and tread on rolling resistance

\begin{tabular}{|c|c|c|c|}
\hline \multirow{2}{*}{ Tire construction } & \multicolumn{2}{|c|}{ Rubber } & \multirow{2}{*}{$R_{0}$} \\
\hline & Tread & Carcass & \\
\hline $\begin{array}{l}1 \\
2 \\
3 \\
4 \\
4\end{array}$ & $\begin{array}{l}\mathrm{NR} \\
\mathrm{NR} \\
\mathrm{SBR} \\
\mathrm{SBR} \\
\mathrm{SBR}\end{array}$ & $\begin{array}{l}\mathrm{NR} \\
\mathrm{SBR} \\
\mathrm{NR} \\
\mathrm{SBR}\end{array}$ & $\begin{array}{l}2.84 \times 10^{-3} \\
4.88 \\
5.54 \\
6.26\end{array}$ \\
\hline
\end{tabular}

TABLE 10. Effect of rubber and carbon black on coefficient of rolling resistance $e^{\mathrm{a}}$

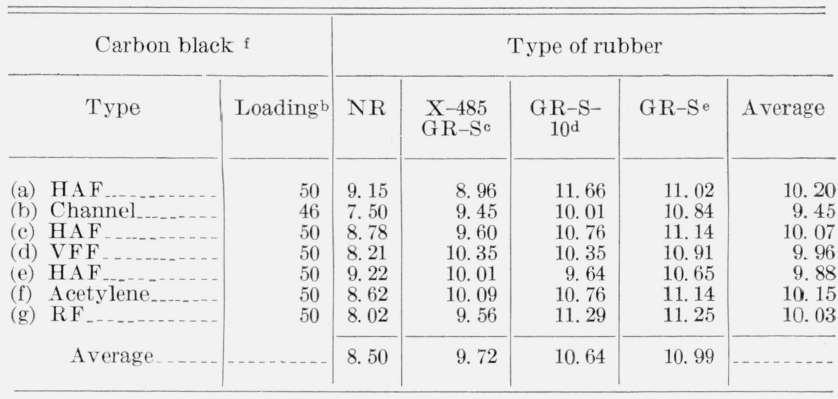

a Speed: $45 \mathrm{mph}$; load: $3,450 \mathrm{lb}$; inflation pressure: $65 \mathrm{psig}$ at $100^{\circ} \mathrm{F}$; $9.00-20$, 10-ply truck tires. Values in the body of the table are rolling resistance multiplied by 1,000 .

b Parts by weight per 100 parts rubber.

c SBR-1500 type.

d SBR-1002

eSBR-1000. furnace.

Measurements were also made comparing polybutadiene and $\mathrm{X}-578 \mathrm{GR}-\mathrm{S}$ (similar to SBR 1500) in $7.00-15$ passenger car tires. The results given in table 11 show that the rolling resistance for polybutadiene tires is appreciably lower than that for $\mathrm{X}-578 \mathrm{GR}-\mathrm{S}$.

TABLE 11. Effect of rubber and black on $R$ in passenger car tires

\begin{tabular}{|c|c|c|}
\hline Rubber & $\begin{array}{l}\text { Carbon } \\
\text { black a }\end{array}$ & $\begin{array}{l}\text { Coefficient } \\
\text { of rolling } \\
\text { resistance b }\end{array}$ \\
\hline Polybutadiene......... & $\mathrm{HAF}$ & 9. 03 \\
\hline $\mathrm{X}-578 \mathrm{GR}-\mathrm{S}^{\mathrm{c}}$ & $\begin{array}{l}\text { SAF } \\
\text { HAF } \\
\text { SAF }\end{array}$ & $\begin{array}{l}11.89 \\
10.75 \\
13.03\end{array}$ \\
\hline
\end{tabular}

${ }^{\text {a }} \mathrm{HAF}=$ high abrasion furnace; $\mathrm{SAF}=$ super abrasion furnace.

b Speed: $60 \mathrm{mph}$; load: $1,095 \mathrm{lb}$; inflation pressure: 26 psig at $100^{\circ} \mathrm{F} ; 7.00-15$, 4-ply passenger ear tires. Values are rolling resistance multiplied by 1,000 . c SBR-1500 type.

\section{Type of Carbon Black}

Tables 10 and 11 also present data for ascertaining the influence of type of carbon black on rolling resistance or power loss. A statistical analysis of the data in table 10 indicates that the type of black has little effect. On the other hand, the data in table 11 show that there is a pronounced difference between HAF and SAF blacks in their effect on power loss.

This complicated and confusing situation apparently results from a balancing of the relative effects of black on modulus and resilience. The poor corre- 
lation between laboratory tests for resilience or power loss on rubber compounds and tire performance is probably attributable to the same cause. Further systematic investigation is needed in order to devise a reliable laboratory test using small specimens of the compounds present in tires. Nevertheless, it may be concluded from the present study that the effects of black on abrasion resistance and power loss are not correlated. Consequently, it is possible to utilize to the fullest extent any advantage of a particular black with respect to abrasion resistance without necessarily affecting power loss adversely.

\section{Type of Cord}

The power loss studies reported thus far were made with tires having rayon cords. These tires were made in the late forties and early fifties. In 1958, a few measurements were made with 10.00-20, 12 ply rating commercial heavy duty truck tires having rayon, nylon, and wire cords. These tires were not made by the same manufacturers so that the results include not only the influence of cord, but the influence of rubber compounds and constructional geometry as well. Nevertheless, the study indicated the following pattern for the coefficient of rolling resistance with speed and load:

\begin{tabular}{|c|c|c|c|}
\hline & Rayon & Nylon & Wire \\
\hline $\begin{array}{l}\text { Increasing speed } \\
\text { Increasing load } \\
\text { Rolling resistance. }\end{array}$ & $\begin{array}{l}\text { Constant } \\
\text { Increase }\end{array}$ & 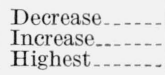 & $\begin{array}{l}\text { Decrease. } \\
\text { Constant or decrease. } \\
\text { Lowest. }\end{array}$ \\
\hline
\end{tabular}

It is interesting to note that the rolling resistance of the tire having wire cords tended to decrease as the speed and load increased. This behavior may be associated with constructional features of the tire rather than the wire cords. If so, future developments may lead to similar behavior of the tires having textile cords.

Another study was made with 8.00-15, 4-ply passenger car tires having rayon or nylon cords and the same rubber compounds in both. Three tires of each type were tested under a load of $1,385 \mathrm{lb}$. and at speeds of $25,40,55$, and $70 \mathrm{mph}$.

Figure 8 shows the change in coefficient of rolling resistance with speed at inflation pressures of 25and 30-psi gage. The values of $R$ for rayon tires are 10 to 15 percent lower at $25 \mathrm{mph}$, but they increase much more rapidly with speed. At $70 \mathrm{mph}$ and higher, they equal or exceed those for nylon tires. In view of the diverse patterns exhibited by rayon truck tires, the sharp increase in $R$ with increasing speed is probably an interaction between the particular geometrical construction used and rayon cords. Other constructions may not show this pattern, but it is likely that improved constructions will be favorable in both rayon and nylon tires. In this connection, it is important to note that the coefficients of rolling resistance for passenger car tires are much greater than those for truck tires.

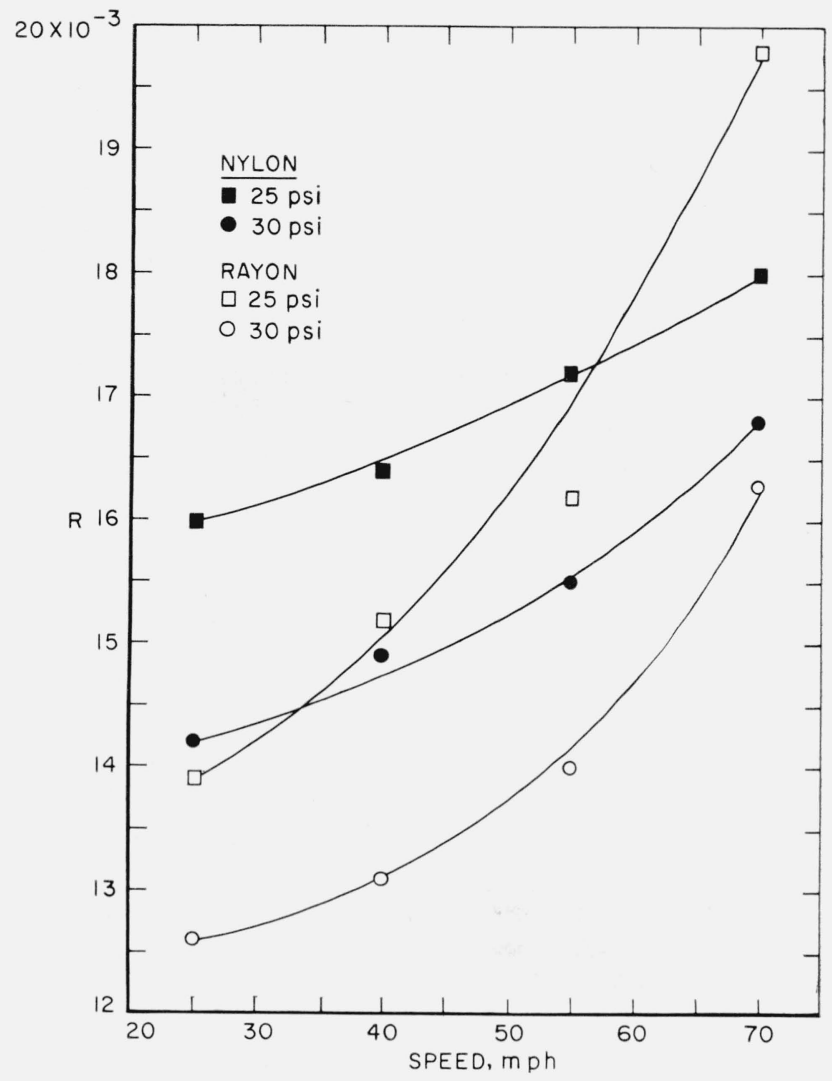

Figure 8. Comparison of rayon and nylon cords in 8.00-15, 4-ply passenger car tires with respect to the coefficient of rolling resistance, $R$, at various speeds.

\section{Relation Between Power Loss and Temperature of Air Within Tire}

In all the experimental work described in this paper, measurements of internal air temperature were made along with the measurements of power loss. Because the rise in temperature is often considered a measure of power loss, a detailed study was made of the relation between temperature rise and power loss. To this effect, the ratio of these two quantities, denoted as $\Delta T / P$, was examined as a function of speed, load, inflation pressure, and tire brand or construction.

An examination of the data showed that, for a given tire, the ratio $\Delta T / P$ was essentially a function of the product of speed and load. For example, a speed of $40 \mathrm{mph}$ at a load of 1,000 lb gave practically the same value for $\Delta T / P$ as a speed of $10 \mathrm{mph}$ at a load of 4,000 lb. No explanation is available for this relationship, but the tires of experiments $\mathrm{A}$ and $\mathrm{B}$ conform to it. Figure 9 is a typical plot of $\Delta T / P$ versus the speed $X$ load product, where $\Delta T / P$ is expressed in Fahrenheit degrees per horsepower and $S L$ is expressed in mile-pounds per hour. The curves are statistically fitted in accordance with the following empirical relationship: 


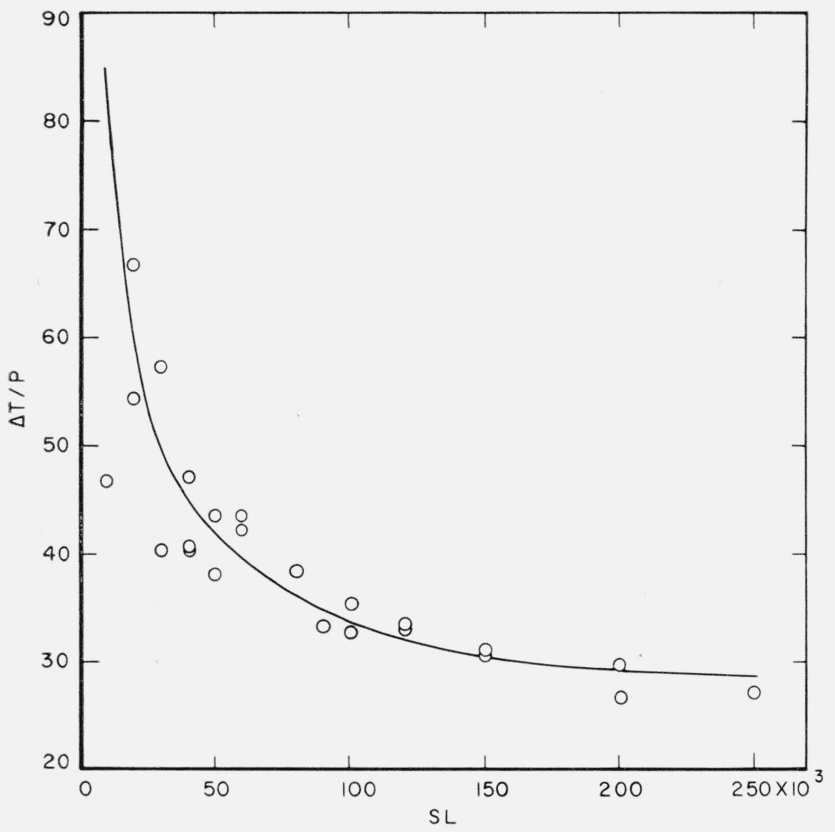

Figure 9. Relationship for brand 1, 10.00-20, 12-ply truck tire between temperature rise of air within tire/unit power loss, $\Delta T / P$ in fahrenheit degrees/horsepower, and the product of speed and load, SL in $l b-m i / h r$.

The solid curve represents the equation $\Delta T / P=23.3+100,400 /(S L)^{0.8}$.

$$
\frac{\Delta T}{P}=G+\frac{H}{(S L)^{0.8}}
$$

where $G$ and $H$ are parameters characteristic of the tire.

The exponent 0.8 for speed is in accord with other equations for heat transfer between solids and gases. In connection with load, there is no prior basis for its use. However, an exponential power of load might be expected from the increase in contact area between tread and roadway with increase in load. The curves derived from this equation represent the experimental points well. A statistical analysis confirms this conclusion by showing that departures from the curves are within experimental error.

It is interesting to note that under usual running conditions (e.g., at speed-load products exceeding $100,000)$ the relation between $\Delta T / P$ and speed or load tends to become constant, approaching a value of approximately $28^{\circ} \mathrm{F} / \mathrm{hp}$. Thus, unless a sufficiently large range of speed and load values are included in the study of temperature-power loss relationship, it is easy to conclude that the ratio of these two quantities is essentially independent of speed and load.

Table 12 contains the best values for the parameters $G$ and $H$ in eq (5), for the four constructions in experiment $\mathrm{A}$ and the five brands in experiment $\mathrm{B}$. It is worth noting that in experiment $A$, the value of $H$ appears to group the four types of tires into two classes, according to the type of rubber in the tread,
TABLE 12. Parameters in equation: $\Delta T / P=G+H /(S L)^{0.8}$

\begin{tabular}{|c|c|c|c|}
\hline Experiment & $\begin{array}{c}\text { Brand or } \\
\text { type }\end{array}$ & $G$ & $H$ \\
\hline $\mathrm{A} \ldots$ & $\begin{array}{l}1 \\
2 \\
3 \\
4\end{array}$ & $\begin{array}{l}22.6 \\
24.6 \\
22.7 \\
23.6\end{array}$ & $\begin{array}{r}132,900 \\
106,500 \\
68,600 \\
72,200\end{array}$ \\
\hline B $\ldots$ & $\begin{array}{l}1 \\
2 \\
3 \\
4 \\
5\end{array}$ & $\begin{array}{l}23.3 \\
26.6 \\
23.4 \\
24.6 \\
26.1\end{array}$ & $\begin{array}{r}100,400 \\
88,700 \\
101,300 \\
83,400 \\
96,700\end{array}$ \\
\hline
\end{tabular}

whereas the value of $G$ groups them in accordance with the type of rubber in the carcass (see table 9).

The relationship between $\Delta T / P$ and $S L$ for brands 1,3 , and 4 is the same within experimental error. Similarly, the relationship for brands 2 and 5 is the same, and higher than that for the other brands. These parameters are apparently not correlated with power loss. It is suspected that the thermal conductivity of the tread and carcass is responsible for the difference but proof is lacking for this supposition.

This supposition is based on an examination of eq (5). The ratio $\Delta T / P$ is a measure of the thermal resistance of the tire and can be divided into two parts. The term $G$ represents that portion of the thermal resistance which is independent of speed and load; whereas, the term $H /(S L)^{0.8}$ represents that portion which is dependent on speed and load. The internal characteristics of the tire such as the thermal resistance of the rubber and cord should be independent of speed and load and represented by $G$. The external characteristics such as ambient air film resistance, direct thermal resistance at the drum through the tire tread, etc., should be dependent on speed and load. It is important to note that at values of $S L$ near 25,000 the thermal resistance is about equally affected by both terms of the equation. At higher $S L$ values the term $G$ becomes the predominant one and as the speed and load approach the range of normal operation the term $H /(S L)^{0.8}$ becomes less than 25 percent of the total thermal resistance. Hence, one would expect devices such as ribs, holes, etc., in the tread or shoulder to be of little or no practical value in reducing the thermal resistance of tires whereas reductions in the thermal resistance of the rubber may result in a very significant decrease in the operating temperature of the tire for the same power loss.

Surprisingly, changes in inflation pressure or in the type of cord have little or no effect on the ratio $\Delta T / P$. It is essentially the same for rayon, nylon, and wire cord tires. This observation indicates that the cord does not have an appreciable effect on the thermal resistance of the tire. The limiting factor appears to be the thermal conductivity of the rubber compounds. This conclusion is substantiated by the small effect of slip on the temperature rise of the contained air, $\Delta T$, when power loss, $P$, is markedly increased as in cornering. 


\section{Discussion}

A comparison of these results with those in the literature indicates qualitative agreement in most instances. There are pronounced quantitative differences which may arise from one or more of the following sources:

1. Power loss of most published data includes windage of the tire.

2 . The drum deceleration and road test methods used by some workers do not permit measurements under steady state conditions.

3. Previous studies include a more limited range of load conditions.

4. The flexure and power loss of tires is greater when run on the outside circumference of a steel drum than when run on a flat surface.

5. The design and construction of tires during the past 40 yr has markedly changed.

6 . The inherent difficulty and error in making power loss measurements are relatively large.

No attempt is being made to discuss these differences here. Nevertheless, the results indicate the need for further study both on the method of measuring power loss and on the performance characteristics of tires. The need for such measurements is greater today than ever with the many new polymers and cords, unconventional constructions, etc., that are being considered for tire use. Reliable power loss measurements provide a valuable tool for new tire design and development.

\section{Conclusions}

The effects of speed, load, and inflation pressure on power loss or rolling resistance $(R)$ are intimately connected with the constructional design of the tire. For rayon truck tires, $R$ seems to be linearly related to speed, load, and reciprocal pressure. The type of rubber has a pronounced effect, but two types of rubber in the same tire interact so that the rolling resistances are not additive. On the other hand, the type of black may or may not have an influence. The type of cord influences $R$, but the effect involves the constructional design. Truck tires appear to have a lower $R$ than passenger car tires. The operating temperature of a tire depends on the power loss, thermal conductivity of the rubber, spead, load, and ambient temperature. The type of cord and the inflation pressure appear to have little effect on thermal resistance.

These studies were supported in part by the Reconstruction Finance Corporation and its successor, the Federal Facilities Corporation. The special tires for experiment A were supplied through the courtesy of the B. F. Goodrich Co. Many members of the National Bureau of Standards staff contributed to various phases of these studies. The assistance of all persons concerned is gratefully appreciated.

\section{References}

[1] W. L. Holt, P. L. Wormeley, Power losses in automobile tires, Tech. Pap. BS 16, 451 (1922); Dynamometer tests of automobile tires, ibid. 17, 559 (1923); Effect of tire resistance on fuel consumption, ibid. 19, 213 (1925).

[2] W. F. Billingsley, R. D. Evans, W. H. Hulswit, E. A Roberts, Rolling resistance of pneumatic tires as a factor in car economy, S.A.E. Journal 50, 37 (1942).

[3] R. D. Evans, Factors affecting the power consumption of pneumatic tires, Proc. 2d Conf. Rubber Technol., p. 438 (London, 1948)

[4] G. G. Richey, R. H. Hobks, R. D. Stiehler, Temperature studies of the air in a truck tire, Rubber Age $\mathbf{7 9}$, 273 (1956).

[5] F. W. Schwab, E. Wichers, Freezing temperature of benzoic acid as a fixed point in thermometry, J. Research NBS 34, 333 (1945) RP 1647.

[6] J. Mandel, M. N. Steel, R. D. Stiehler, Treadwear of tires, influence of type of rubber and black, Ind. Eng. Chem. 43, 2901 (1951).

Washington, D.C.

(Paper 64C1-18) 